\title{
Development and in vitro Characterization of Gastroretentive Formulations as Calcium Pectinate Hydrogel Pellets of Pregabalin by Ionotropic Gelation Method
}

\author{
Rukiye Sevinç Özakar* \\ Department of Pharmaceutical Technology, Faculty of Pharmacy, Atatürk University, Erzurum, TURKEY.
}

\begin{abstract}
Introduction: Pregabalin (PG) is primarily prescribed for epilepsy, painful diabetic neuropathy, post-herpetic neuralgia, and fibromyalgia. Also, it is used in clinical practice to treat general anxiety disorder due to its anxiolytic properties. Pectin is a watersoluble ionic polysaccharide. As a result of the interaction of pectin with calcium ions, a hydrophilically coated insoluble carrier system is formed by complexing between surfaces, which provides a sustained release. In this direction, floating hydrogel pellets containing PG were developed and characterized in our study. This study aimed to make a sustained release of PG, reach the optimum level in characterization, and bring a new approach to widely used oral drug therapy. Materials and Methods: PG was a gift from Ilko Pharmaceuticals (Turkey) and pectin was purchased from CPKelco (USA). The ionotropic gelation technique was used to prepare pellets. To characterize the pellets, flotation/swelling degrees, yield, drug loading capacity/encapsulation efficiency, particle size/distribution, in-vitro release/kinetics, and morphological studies have been done. Also, the structural features of pellets have determined via the Fourier Transform Infrared (FT-IR), scanning electron microscopy (SEM), Brunauer-Emmett-Teller (BET), and X-ray diffraction (XRD) studies. Results: The formulations have been successfully developed without using any coating agent to prolong drug release for $24 \mathrm{~h}$ with an encapsulation efficiency of $\sim 82 \%$. Optimum results were obtained in characterization studies. As a result of BET analysis, it has been proven that the structure is porous and there is no change in the chemical and crystal structure of PG by FT-IR and XRD studies. Conclusion: We anticipate that the formulation we developed will provide an alternative to the sustained-release PG preparations in the current pharmaceutical market.

Key words: Gastroretentive drug delivery, Pregabalin, Pectin, HPLC, FT-IR, BET, XRD.
\end{abstract}

\section{INTRODUCTION}

Oral drug delivery is the most widely used of all the routes of administration investigated for the systemic delivery of drugs using different dosage forms for decades. Therefore, new carriers are being developed for the oral delivery of drugs. Solid dosage forms are advantageous in terms of low cost, ease of administration, exact dosing, and most importantly, patient compliance. ${ }^{1,2}$ However, there are also disadvantages such as the short residence time of the dosage forms in the gastrointestinal tract, unpredictable gastric emptying, and degradation of active substances due to the high activity of the gastrointestinal content. Gastric emptying is a complex process and makes the performance of drug delivery systems uncertain in "in vivo" studies. Floating drug systems are useful systems that can prevent these uncertainties by increasing the duration of drug delivery systems in the stomach. Floating systems, or hydrodynamically controllable systems, are low-density systems with sufficient lifting power that can float for an adequate time without being affected by gastric content
Submission Date: 25-06-2021; Revision Date: 10-09-2021; Accepted Date: 28-12-2021.

DOI: $10.5530 /$ ijper.56.1s.38 Correspondence:

Dr. Rukiye Sevinç Özakar Department of Pharmaceutical Technology, Faculty of Pharmacy, Atatürk University, Erzurum, TURKEY.

E-mail: rukiyeso@atauni.edu.tr

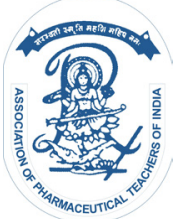

www.ijper.org 
and emptying of the stomach and remain floating in the stomach for a long time..$^{2-4}$ These systems are matrix-type systems prepared with the help of swellable polymers and various effervescent compounds (such as sodium bicarbonate $\left(\mathrm{NaHCO}_{3}\right)$, tartaric acid, and citric acid). These hydrophilic systems are formulated to retain gas and release carbon dioxide $\left(\mathrm{CO}_{2}\right)$ when they encounter acidic gastric juice. They become floatable by trapping this gas through hydrogels that exhibit swelling. ${ }^{5,6}$ Floating systems can release active ingredients at the desired rate while floating on the surface of the gastric contents. When the release of the active substance is over, the residues of the system are removed together with the stomach contents. ${ }^{2-4}$

PG is a white and crystalline powder that dissolves in acidic, basic, and aqueous solutions. It has anticonvulsant (antiepileptic) properties. ${ }^{78}$ PG (3-amino methyl hexanoic acid) is similar to gamma-aminobutyric acid (GABA), which is the neurotransmitter of mammals with both structural and pharmacological properties. It started to be used in the early 1990s. Its primary effect is anticonvulsant, and it is used in epilepsy. ${ }^{9,10}$ Its mechanism of action is still not fully resolved, although it has been found to bind to the calcium channel in the central nervous system and reduce calcium flow at the nerve endings. Thus, it is thought to change the release of neurotransmitters that reduce the communication between nerves and be effective in neuropathic pain and epilepsy seizures. PG is still not registered in any pharmacopeia. ${ }^{7,10}$ PG has many advantages compared to other antiepileptics. It does not have pharmacokinetic interactions with other drugs or is induced by enzymes. PG has a variable absorption in the gastrointestinal tract and is preferred to be absorbed from the upper parts of the gastrointestinal tract. ${ }^{11}$ Although used in clinical practice to treat general anxiety disorder due to its anxiolytic properties, it is primarily prescribed for painful diabetic neuropathy, post-herpetic neuralgia, radicular pain, and fibromyalgia. Its doses range from 75 to 150 mg per day for neuropathic pain, and its bioavailability is quite high $(90 \%) .^{12,13}$

Pectin is a water-soluble ionic polysaccharide found naturally in the cell walls of many plants and contains $\alpha$-D-galacturonic acid in straight chains. Lowmethoxylated amidated pectin (degree of esterification $<50 \%$ ) forms a more robust gel structure by crosslinking galacturonic acid chains under the effect of calcium. ${ }^{14-16}$ In the preparation of delivery systems containing pectin, especially ionotropic gelation, and gel coating technique is frequently used. Both of these techniques are safe for the risk of toxicity. ${ }^{17}$ In the ionotropic gelation technique, polysaccharides (such as pectin) are dissolved in water or a weakly acidic medium. These solutions are then added dropwise into solutions containing oppositely charged ion, which is constantly stirred. During complexation with oppositely charged ions, polysaccharides undergo ionic gelation and precipitate as spherical particles. The pellets formed are filtered, washed with distilled water, and dried. Solvent toxicity and other undesirable effects are prevented by crosslinking by electrostatic interaction instead of chemical crosslinking. ${ }^{18,19}$ Pectinate hydrogels formed in the presence of calcium are stable in low $\mathrm{pH}$ solutions and swell in weak basic solutions. ${ }^{20}$ Calcium pectinate is disintegrated by pectinolytic enzymes in the colon and delays drug release since it cannot dissolve in the upper gastrointestinal tract (cannot be broken down by gastric or intestinal enzymes, it is resistant to protease and amylase enzymes). As a result of the interaction of pectin with calcium ions, an insoluble carrier system is formed, which is hydrophilically coated by interfacial complexation, and this ensures sustained release. ${ }^{15,16,21}$

Pellets are multi-unit solid drug forms, with particle sizes generally ranging from $0.5-1.5 \mathrm{~mm}$. Each particle is a matrix obtained by dispersing the active substance in the polymer. ${ }^{22}$ Among the advantages of pellets are that the substances forming the pellets do not separate from each other during transportation; they can be packaged homogeneously. They do not have a high local concentration because they are dispersed in the stomach immediately. With pellets, drugs with different release properties and/or incompatible drugs or physically opposite materials can be combined, and dissolution can be achieved at the desired rate by controlled release or extended release. . $^{23,24}$

In this study, floating pellet systems, one of the new drug delivery systems that have been studied frequently today, were developed and characterized for PG and bring a new approach to widely used oral drug therapy. For the characterization of floating pellets, flotation and swelling degrees, yield, drug loading capacity and encapsulation efficiency, particle size and size distribution, in-vitro release and release kinetics, and morphological-organoleptic control studies have been done. Also, the structural features of the floating pellets were determined via the Fourier Transform Infrared (FTIR) spectroscopy, scanning electron microscopy (SEM), Brunauer-Emmett-Teller (BET), and X-ray diffraction (XRD) studies. It is aimed to create a sustained release and decrease the daily dose intake of the patient via these formulations. It is also possible to reduce the occurrence of side effects and/or toxic effects and increase patient compliance with less dosing frequency in the future. 


\section{MATERIALS AND METHODS}

\section{Materials}

PG was a gift from İlko Pharmaceuticals (Ankara, Turkey). Low-methoxylated amidated pectin $\left(\mathrm{GENU}^{\circledR}\right.$ LM 104) was purchased from CPKelco (Atlanta, USA). Calcium chloride $\left(\mathrm{CaCl}_{2}\right)$ and potassium chloride were purchased from J. T. Baker (Deventer, Holland) and Riedel-de-Haën (Germany), respectively. Sodium hydroxide, sodium bicarbonate, potassium dihydrogen phosphate, and potassium hydroxide were purchased from Merck (Darmstadt, Germany). Hydrochloric acid $(\mathrm{HCl})$ and HPLC grade solvents, including methanol, and acetonitrile were purchased from Isolab (Germany) and Sigma-Aldrich (Germany). Ultrapure water was

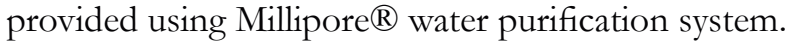

\section{Methods}

\section{Development of the Quantification Method for Pregabalin}

The quantification method for PG developed by Mohan et al. was modified and re-developed. ${ }^{25}$ PG was quantified using a validated High Pressure Liquid Chromatography (HPLC-Shimadzu Prominence LC-20A) method. Standard solutions containing PG were prepared in ultrapure water at a concentration of $200 \mu \mathrm{g} / \mathrm{mL}$, and a calibration curve was drawn from 11 points by making the necessary dilutions $(1-200 \mu \mathrm{g} / \mathrm{mL})$. Freshly prepared phosphate buffer was filtered using a $0.45 \mu \mathrm{m}$ Whatman filter paper, and the mobile phase was degassed for 5 min in the ultrasonic water bath. HPLC conditions are given in Table 1.

\section{Validation of the Quantification Method}

Analytical method validation is the verification of the developed method. It ensures that the developed method achieves appropriate, repeatable, and reliable results for the desired targets. According to the rules of ICH Q2 (R1), the developed method has been validated for linearity, accuracy, precision, the limit of detection

\begin{tabular}{|c|c|}
\hline Mobile Phase & $\begin{array}{l}\text { Phosphate Buffer-USP30/NF25 (pH } \\
\text { adjusted to } 6.5 \text { using potassium } \\
\text { hydroxide):MeOH:ACN, } 75: 10: 15\end{array}$ \\
\hline Column & $\begin{array}{c}\text { RP-C }_{18}, \text { Silicyle }^{\circledR} \text { SiliaChrom, } \\
150 \times 4.6 \mathrm{~mm}\end{array}$ \\
\hline Detector & PDA \\
\hline Wavelength & $197 \mathrm{~nm}$ \\
\hline Column Temperature & $25^{\circ} \mathrm{C}$ \\
\hline Injection Volume & $20 \mu \mathrm{L}$ \\
\hline Flow Rate & $0.7 \mathrm{~mL} / \mathrm{min}$ \\
\hline
\end{tabular}

(LOD), the limit of quantification (LOQ), and selectivity (specificity). ${ }^{25-28}$ Standard solutions of PG at 20, 80, and $160 \mu \mathrm{g} / \mathrm{mL}$ were prepared for inter-day and intra-day accuracy and precision by replicate analysis of on a day and three consecutive days.

\section{Preparation of Floating Pregabalin Hydrogel Pellet Formulations}

The ionotropic gelation method was used in the preparation of floating hydrogel pellets. ${ }^{29-31}$ First of all, the different amounts of pectin were swelled homogeneously on a multi-point magnetic stirrer (2mag, MIX 15 eco) at $750 \mathrm{rpm}$ in ultrapure water. Then, while mixing at the same speed, $\mathrm{PG}$ and $\mathrm{NaHCO}_{3}$ (as a source of $\mathrm{CO}_{2}$ ) were added in determining amounts, and it was completely dissolved. These prepared dispersions were dropped with the help of a 26 Gauge syringe into the mixing $\mathrm{CaCl}_{2}$ solution at determined concentrations $(0.1,0.2$, and $0.3 \mathrm{M})$ from a certain height. In order to form pellets in the gel structure and complete the complexation, dispersions were mixed for a period of more time. After the hydrogel pellets were formed, filtration was applied. Then, the pellets were washed several times with pure water and frozen overnight at $-20^{\circ} \mathrm{C}$. The lyophilization (CHRIST Alpha 2-4 LSC plus) was applied for $24 \mathrm{~h}$, and the obtained dried pellets for the later experiments were stored at room temperature in the desiccator (minimum. $n=3$ ). PG-free pellets (blank pellets-B) were also prepared without the PG addition only, as described above.

\section{In vitro Characterization of Floating Pregabalin Hydrogel Pellet Formulations}

\section{Determination of Flotation Degrees}

To mimic the in vivo gastric retention, the flotation degree determination of hydrogel pellets with and without PG was performed using a $50 \mathrm{~mL}$ pH $1.2 \mathrm{HCl}$ buffer (USP30/NF25) in a $37^{\circ} \mathrm{C}$ horizontal shaker water bath (Memmert, WNB 14). A certain number (such as 100-150 pieces) of lyophilized pellets were placed in this medium, and those on the surface at certain time intervals (such as $5 \mathrm{~min}, 30 \mathrm{~min}, 1 \mathrm{~h}$ ) were counted. This study was continued for $24 \mathrm{~h}$. The flotation degree of the formulations was determined by proportioning the number of floating pellets over time and the number of non-floating pellets (minimum. $n=3$ ). ${ }^{32}$ The percentage of flotation degree was calculated by using the formula below:

Flotation Degree $\%=\frac{\text { Number of floating hydrogel pellets over time }}{\text { Number of initial hydrogel pellets }} \times 100$ 


\section{Determination of Yield, Drug Loading Capacity, and Encapsulation Efficiency}

The floating hydrogel pellets containing PG were mixed in a $5 \mathrm{~mL}$ mobile phase and stirred for $2 \mathrm{~h}$ on a multipoint magnetic stirrer (2mag, MIX $15 \mathrm{eco}$ ) at $750 \mathrm{rpm}$ for the pellets' degradation of the crosslinked structure, and then PG came into the open. Subsequently, the supernatant was separated, filtered through a $0.45 \mu \mathrm{m}$ membrane filter, and quantified by using the validated HPLC method (minimum. $n=3$ ). All dilutions were made with the mobile phase. ${ }^{33}$ The percentages of yield, drug loading and encapsulation efficiency were calculated by using the formulas below:

Yield $\%=\frac{\text { Practically obtained total amount of formulation }}{\text { Total amount of theoretically added components }} \times 100$

Drug Loading $\%=\frac{\text { Theoretical PG amount }- \text { Practical PG amount }}{\text { Amount of obtained floating hydrogel pellets }} \times 100$

Encapsulation Efficiency $\%=\frac{\begin{array}{l}\text { Theoretical PG amount } \\ \text { Practical PG amount }\end{array}}{\text { Theoretical PG amount }} \times 100$

\section{Determination of Swelling Degrees}

For the swelling degree study, $50 \mathrm{mg}$ of lyophilized samples from the floating hydrogel pellet formulations with and without PG were weighed and carried out for $24 \mathrm{~h}$ in $30 \mathrm{~mL}$ pH $1.2 \mathrm{HCl}$ buffer (USP30/NF25) using a horizontal shaker water bath (Memmert, WNB 14) set at $37^{\circ} \mathrm{C} / 50 \mathrm{rpm}$. Swelling pellets at the specified time intervals (such as $30 \mathrm{~min}, 1 \mathrm{~h}, 2 \mathrm{~h}$ ) were filtered and weighed. The degree of swelling after the experiment was evaluated by calculating the difference between the dry weight before swelling and the subsequent wet weight in $\%$, and the increase in weight was determined (minimum. $n=3$ ). ${ }^{21,34}$ The percentages of swelling degree was calculated by using the formula below:

$$
\text { Swelling Degree \% }=\frac{\begin{array}{l}
\text { Weight of swollen floating hydrogel pellets } \\
\text { Initial weight }
\end{array}}{\text { Initial }} \times 100
$$

\section{Determination of Particle Size and Size Distribution of Wet-Dry Pellets}

The sizes of freshly prepared and lyophilized PG containing and blank floating hydrogel pellets were measured from each series using a manual vernier caliper (minimum. $n=30) \cdot{ }^{35}$

\section{In-vitro Release Study and Determination of Release Kinetics}

Floating hydrogel pellets containing a certain amount of PG were placed in a horizontal shaker water bath (Memmert, WNB 14) set at $37^{\circ} \mathrm{C} / 50 \mathrm{rpm}$ containing $50 \mathrm{~mL}$ pH $1.2 \mathrm{HCl}$ buffer (USP30/NF25), and the release was carried out for $24 \mathrm{~h}$. An appropriate amount of samples were withdrawn at certain time intervals (such as $5 \mathrm{~min}, 30 \mathrm{~min}, 1 \mathrm{~h}$ ), and subsequently, the same amount of fresh buffer medium was added to the samples to maintain the sink conditions. Samples were filtered through $0.45 \mu \mathrm{m}$ membrane filters, and released PG amounts were determined by a validated HPLC method. ${ }^{36}$ Release results in $\mathrm{pH} 1.2 \mathrm{HCl}$ buffer were applied to the computer program in order to determine the kinetic model of the release from the selected hydrogel pellets containing PG. Whether formulations are compatible with Zero-Order, FirstOrder, Korsmeyer-Peppas, or Higuchi kinetic models were determined by mathematical operations and formulas. ${ }^{37,38}$

\section{Morphological-Organoleptic Control}

Properties such as shape, size, homogeneity, color, transparency, and surface of wet and dry floating hydrogel pellet formulations have been visually evaluated. Digital photos were also taken. The presence of pores in the pellets, the roughness or smoothness of their surfaces were also investigated using a scanning electron microscope (SEM, Zeiss Gemini Sigma 300). Since our formulations are insulating, they were examined after being covered with a thin layer $(100 \AA)$ with gold. ${ }^{39}$ This study was performed at East Anatolian High Technology Research and Application Center (DAYTAM, Erzurum).

\section{Determination of Surface Area and Pore Analysis}

The surface area, average pore diameter (Brunauer, Emmett, and Teller (BET) method) and pore volume, pore size distribution (Barrett-Joiner-Halenda (BJH) method) for blank and PG-containing floating hydrogel pellets were obtained by using nitrogen adsorption isotherms using a Micromeritics 3Flex analyzer. The system temperature was maintained at $77^{\circ} \mathrm{C} .4^{40}$ This study was performed at East Anatolian High Technology Research and Application Center (DAYTAM, Erzurum).

\section{Fourier Transform Infrared Spectroscopy (FT-IR) Study}

Powder samples of PG, pectin, $\mathrm{CaCl}_{2}, \mathrm{NaHCO}_{3}$, and pellet formulations were prepared to determine if there were any unwanted interactions between the formulation ingredients and the active ingredient. Infrared spectra 
were taken by FT-IR (ATR) spectrophotometer directly over the powder sample in the range of $4000-400 \mathrm{~cm}^{-1}$ wavenumber. ${ }^{33}$ This study was performed at East Anatolian High Technology Research and Application Center (DAYTAM, Erzurum).

\section{X-Ray Diffraction (XRD) Study}

The crystallinities of PG and PG-containing floating hydrogel pellet formulation were determined by the XRD method. XRD studies were carried out using an $\mathrm{X}$-ray diffractometer (PANalytical Empyrean XRD) fitted with a copper target, a voltage of $45 \mathrm{kV}$, and a current of $40 \mathrm{~mA} .{ }^{41}$ This study was performed at East Anatolian High Technology Research and Application Center (DAYTAM, Erzurum).

\section{RESULTS AND DISCUSSION}

\section{Development of the Quantification Method for Pregabalin}

The HPLC method has been developed successfully. A calibration curve was drawn from 11 points (1, 5, $10,25,50,75,100,125,150,175,200 \mu \mathrm{g} / \mathrm{mL}$ ) with samples prepared from the stock solution so that the measurements were more precise. In the equation obtained, $R^{2}$ was determined to be 0.9999 . The calibration curve and chromatogram of PG are given in Figure 1 below.

\section{Validation of the Quantification Method}

All the validation parameters were found to be within limits according to ICH Q2 (R1). After the method quantification, validation was initiated and determined that the method showed linearity in the PG dose range between $0.3 \mu \mathrm{g} / \mathrm{mL}$ and $200 \mu \mathrm{g} / \mathrm{mL}$. It was determined that the blank solution containing all components used in formulations except PG was read and did not peak at the same place as PG and the developed method was specific for PG. The sensitivity of the method was determined experimentally that LOD was $0.3 \mu \mathrm{g} / \mathrm{mL}$ and LOQ was $1 \mu \mathrm{g} / \mathrm{mL}$. As a result of the repeatability and reproducibility studies that were carried out for the accuracy and precision of the method, it has been
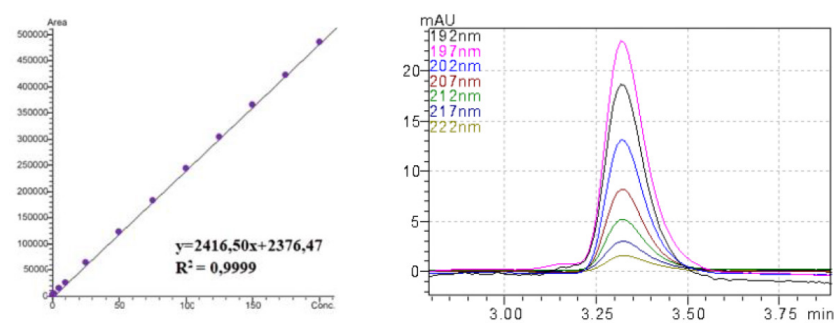

Figure 1: Calibration curve and chromatogram of PG. determined that the $\%$ relative standard deviation and the $\%$ relative error do not exceed $2 \%$. The method developed for PG quantification is sensitive, specific, reproducible, and allows a simple and rapid quantitative determination of PG. Validity has been proven with validation processes. Thus, the data obtained (quantification, $\mathrm{EE} \%$, and in-vitro release results) were evaluated precisely $\left(R^{2}=0.9999\right)$.

\section{Preparation of Floating Pregabalin Hydrogel Pellet Formulations}

Low-methoxylated amidated pectin was chosen in the formulations due to its desirable solubility in water and ease of cross-linkage by the ionotropic gelation method. The ionotropic gelation method in which crosslinking was formed between the divalent calcium ions and the negatively charged carboxyl groups of the pectin molecules has been used successfully in the preparation of calcium pectinate pellets. ${ }^{42}$ These two parameters are essential for the spherical and rigid shape. Also, pellets were prepared without the use of additional equipment and organic solvent, so this technique is speedy and cheap. ${ }^{43}$ As a result of the pre-formulation studies, different combinations were created by changing the formulation components $\left(\mathrm{CaCl}_{2}\right.$ : cross-linker and $\mathrm{NaHCO}_{3}$ : gas-forming agent amount). The presence of $\mathrm{CO}_{2}$ from $\mathrm{NaHCO}_{3}$ molecules in the pellets decreases the density and ensures the pellets with good floating properties. ${ }^{35}$ Pellets were prepared without the use of additional equipment and organic solvent. 12 different hydrogel pellet formulations (blank pellets-B and drugcontaining pellets-D) were obtained in a spherical and rigid structure. But 100\% floating pellets were preferred for our target, and other studies were carried out on these formulations. Used formulation components and quantities are given in Table 2.

\section{In vitro Characterization of Floating Pregabalin Hydrogel Pellet Formulations}

\section{Determination of Flotation Degrees}

All prepared hydrogel pellet formulations were left to float in $\mathrm{pH} 1.2 \mathrm{HCl}$ buffer for 24h. The results are given in Table 3. Considering the results, there have been $6 \mathrm{~B}$ and $6 \mathrm{D}$ hydrogel pellet formulations that started floating as soon as possible (in a few seconds) and were completely floated for $24 \mathrm{~h}$. When the $6 \mathrm{D}$ and $6 \mathrm{~B}$ formulations were examined, it was seen that the amount of $\mathrm{CaCl}_{2}$ and $\mathrm{NaHCO}_{3}$ is the highest. Floating ability is related to the $\mathrm{NaHCO}_{3}$ amount. ${ }^{44}$ It was also thought that the use of pectin as a polymer contributes positively to buoyancy. Cellulose derivatives such as 


\begin{tabular}{|c|c|c|c|c|c|}
\multicolumn{5}{|c|}{ Table 2: Formulation components and quantities. } \\
\hline Formulation & $\begin{array}{c}\text { PG } \\
\text { (mg) }\end{array}$ & $\begin{array}{c}\text { Pectin } \\
(\mathbf{m g})\end{array}$ & CaCl $_{2}$ & $\begin{array}{c}\mathbf{N a H C O}_{3} \\
\text { (mg) }\end{array}$ & $\begin{array}{c}\text { Drug phase: } \\
\text { Aqueous } \\
\text { phase }\end{array}$ \\
\hline 1D & 10 & 40 & $0.1 \mathrm{M}$ & 20 & $1: 5$ \\
\hline 2D & 10 & 40 & $0.1 \mathrm{M}$ & 40 & $1: 5$ \\
\hline 3D & 10 & 40 & $0.2 \mathrm{M}$ & 20 & $1: 5$ \\
\hline 4D & 10 & 40 & $0.2 \mathrm{M}$ & 40 & $1: 5$ \\
\hline 5D & 10 & 40 & $0.3 \mathrm{M}$ & 20 & $1: 5$ \\
\hline 6D & 10 & 40 & $0.3 \mathrm{M}$ & 40 & $1: 5$ \\
\hline 1B & - & 40 & $0.1 \mathrm{M}$ & 20 & $1: 5$ \\
\hline 2B & - & 40 & $0.1 \mathrm{M}$ & 40 & $1: 5$ \\
\hline 3B & - & 40 & $0.2 \mathrm{M}$ & 20 & $1: 5$ \\
\hline 4B & - & 40 & $0.2 \mathrm{M}$ & 40 & $1: 5$ \\
\hline 5B & - & 40 & $0.3 \mathrm{M}$ & 20 & $1: 5$ \\
\hline 6B & - & 40 & $0.3 \mathrm{M}$ & 40 & $1: 5$ \\
\hline
\end{tabular}

\begin{tabular}{|c|c|c|c|c|c|c|c|}
\hline 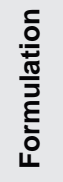 & & 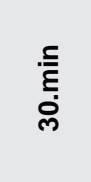 & کَ & స̃ & $\stackrel{f}{f}$ & $\frac{5}{\infty}$ & $\stackrel{5}{\dot{N}}$ \\
\hline 1D & 10 & 10 & 10 & - & - & - & - \\
\hline $2 D$ & 60 & 60 & 60 & - & - & - & - \\
\hline $3 D$ & 12.5 & 12.5 & 12.5 & - & - & - & - \\
\hline 4D & 100 & 100 & 90 & - & - & - & - \\
\hline $5 D$ & 4.16 & 33.3 & 35 & - & - & - & - \\
\hline $6 \mathrm{D}$ & 100 & 100 & 100 & 100 & 100 & 100 & 100 \\
\hline 1B & 11.1 & 72.2 & 70.1 & - & - & - & - \\
\hline $2 B$ & 76.47 & 76.47 & 75.09 & - & - & - & - \\
\hline $3 B$ & 6.25 & 18.75 & 33 & - & - & - & - \\
\hline $4 \mathrm{~B}$ & 80 & 90 & 90 & - & - & - & - \\
\hline $5 B$ & 36 & 96 & 91 & - & - & - & - \\
\hline $6 B$ & 100 & 100 & 100 & 100 & 100 & 100 & 100 \\
\hline
\end{tabular}

HPMC and $\mathrm{NaCMC}$, pectin, and sodium alginate were used as the polymer in a floating bead study by Abou el Ela et al. In the floating study, they were used $\mathrm{pH} 1.2 \mathrm{HCl}$ buffer and observed that the most floating feature was in the formulations containing pectin. ${ }^{45}$ Digital images of the flotation experiment of $6 \mathrm{D}$ formulation are given in Figure 2.

\section{Determination of Yield, Drug Loading Capacity, and Encapsulation Efficiency}

The yield, drug loading capacity, and encapsulation efficiency data of the selected 6B and 6D hydrogel pellet formulations are given in Table 4 (mean \pm SD). The $6 \mathrm{D}$ formulation, which has an encapsulation efficiency

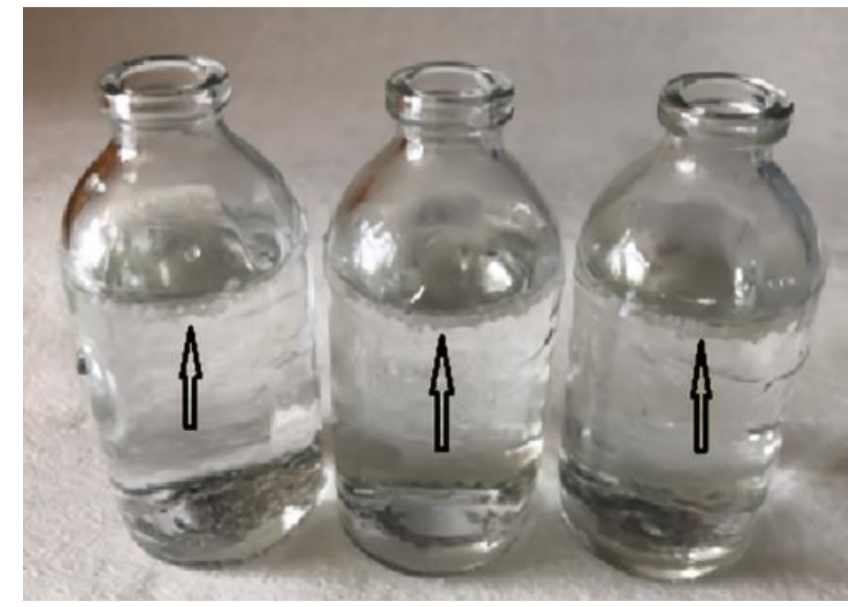

Figure 2: Digital images of the floating ability of 6D formulation.

Table 4: Yield, drug loading capacity and encapsulation efficiency of 6B and 6D formulations.

\begin{tabular}{|c|c|c|c|}
\hline Formulation & $\% \mathrm{Y}$ & $\% \mathrm{DL}$ & $\% \mathrm{EE}$ \\
\hline 6B & $10.74 \pm 1.29$ & - & - \\
\hline 6D & $13.75 \pm 0.58$ & $3.40 \pm 0.51$ & $82.43 \pm 15.45$ \\
\hline
\end{tabular}

\begin{tabular}{|c|c|c|c|c|c|c|}
\hline \multicolumn{7}{|c|}{$\begin{array}{l}\text { Table 5: Swelling degree data of } 6 \mathrm{~B} \text { and } 6 \mathrm{D} \\
\text { formulations (\%). }\end{array}$} \\
\hline 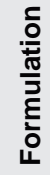 & 产 & f. & న્ & f̆ & $\frac{c}{\infty}$ & ป̊ \\
\hline $6 B$ & 150.00 & 150.60 & 161.80 & 195.07 & 204.40 & 247.73 \\
\hline 6D & 144.87 & 148.21 & 162.00 & 198.33 & 182.33 & 239.87 \\
\hline
\end{tabular}

of over $82 \%$, has been found extremely satisfactory in terms of PG delivery and release.

\section{Determination of Swelling Degrees}

The swelling degree study was carried out on the hydrogel pellet formulations of $6 \mathrm{D}$ and $6 \mathrm{~B}$, which had the best flotation degree from the prepared pellets. The swelling degrees were calculated with the formula given above, and the results are given in Table 5 below (mean $\pm \mathrm{SD}$ ). The digital images of $6 \mathrm{~B}$ and $6 \mathrm{D}$ formulations resulting from the swelling degree study are given in Figure 3, and the swelling degree graph is given in Figure 4. The swelling degree of pellets describes the amount of water contained within the floating hydrogel pellets which is a result of the crosslinking and hydrophilicity. ${ }^{46}$ Due to the use of swellable polymers in floating hydrogel systems, it is important that the volume increase and density decrease due to water absorption in aqueous mediums. The high degree of swelling also increases buoyancy. ${ }^{5}$ The $\sim 250 \%$ swelling of the $6 \mathrm{~B}$ 


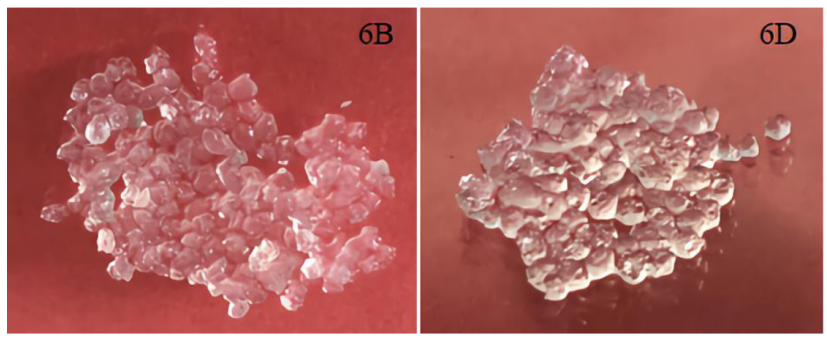

Figure 3: Swelling test results of $6 B$ and $6 D$ formulations after $24 \mathrm{hr}$.

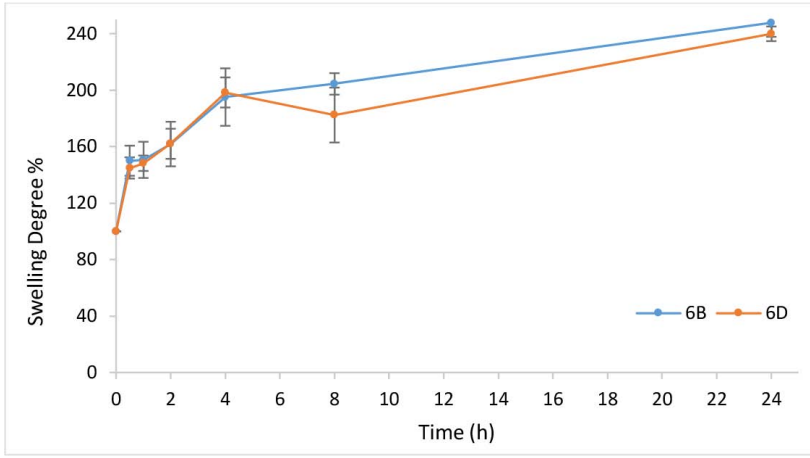

Figure 4: Graph of swelling degrees of 6B and 6D formulations.

\begin{tabular}{|c|c|c|}
\hline Formulation & Freshly prepared $(\mathrm{mm})$ & Lyophilized (mm) \\
\hline $6 B$ & $1.65 \pm 0.11$ & $1.47 \pm 0.22$ \\
\hline 6D & $1.85 \pm 0.12$ & $1.77 \pm 0.14$ \\
\hline
\end{tabular}

and $6 \mathrm{D}$ formulations at the end of $24 \mathrm{~h}$ compared to their first weight also supports this theory (Figure 4). There was no deterioration in the structure of the pellets during the swelling study. So, this indicates that the crosslinking is very strong and very beneficial for prolonged release.

\section{Determination of Particle Size and Size Distribution of Wet-Dry Pellets}

The sizes of the freshly prepared and lyophilized hydrogel pellets of the selected $6 \mathrm{D}$ and $6 \mathrm{~B}$ formulations are given in Table 6 as the mean and standard deviation. Since the standard deviation is very low, we can easily say that its dimensions are very homogeneous. The sizes of PG-containing pellets increased in both fresh and lyophilized compared to empty pellets. In other words, the presence of PG has increased the size. After lyophilization, it is usual for the size to decrease due to the removal of water in the structure of the pellets.

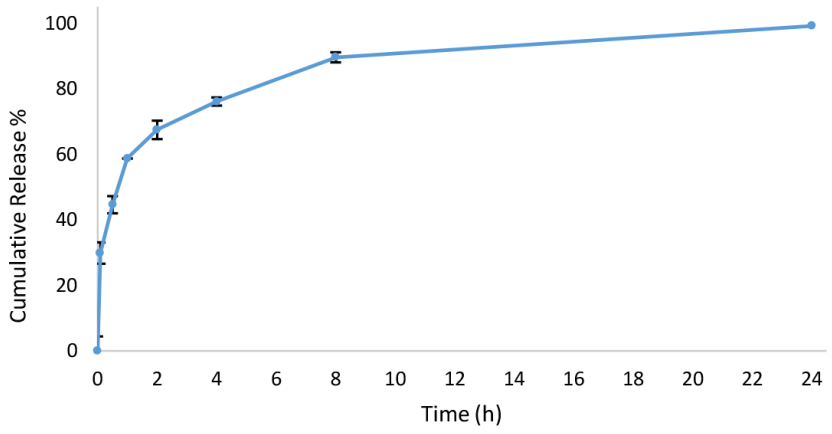

Figure 5: In-vitro release graph of 6D formulation.

\section{In-vitro Release Study and Determination of Release Kinetics}

The graph for release is given in Figure 5. It has been observed that pellets containing PG in the selected 6D formulation show a 'burst effect' in the first 5 min due to the hydrophilic structure of $\mathrm{PG},{ }^{47}$ and then release for $24 \mathrm{~h}$. The burst effect seen in the early stages of the release study was thought to be due to the fact that PG is soluble in water and highly water entering the pores due to the pellets' porous structure. A similar situation can be seen in the study of Whitehead et al. They emphasized that the release of amoxicillin trihydrate from the pores of the beads that they made occurs by diffusion. ${ }^{48}$ This means that we can give the starting dose to the patient in treatment. In many of the sustained-release dosage forms available on the market, the starting dose is formulated separately and is placed in capsules or tablets. In our study, this has been realized spontaneously. Our study has also been gained value when viewed from this angle. Approximately $80 \%$ and $99 \%$ of the PG at the end of $\sim 6$ and $24 \mathrm{~h}$ were released, respectively. We can say that the network structure created by crosslinking prolongs the release of PG because of the calcium salt of pectin. It takes a maximum of $3 \mathrm{~h}$ for solid dosage forms to move from the stomach to the intestine, depending on the stomach content and dosage form. For this reason, gastroretentive systems such as floating drug delivery systems are beneficial for extending the release of drugs. ${ }^{49}$ It has been made possible for the formulation we developed to perform PG release on the gastric fluid surface for $24 \mathrm{~h}$.

The kinetic model of PG release from the selected 6D hydrogel pellet formulation was determined by a computer program. All release kinetics data of $6 \mathrm{D}$ formulation are given in Table 7 below. In the evaluation made on the value of $R^{2}$, it was observed that the $6 \mathrm{D}$ formulation showed a more suitable release for the Korsmeyer-Peppas release kinetic model, which explains the drug release behavior from polymeric systems. 

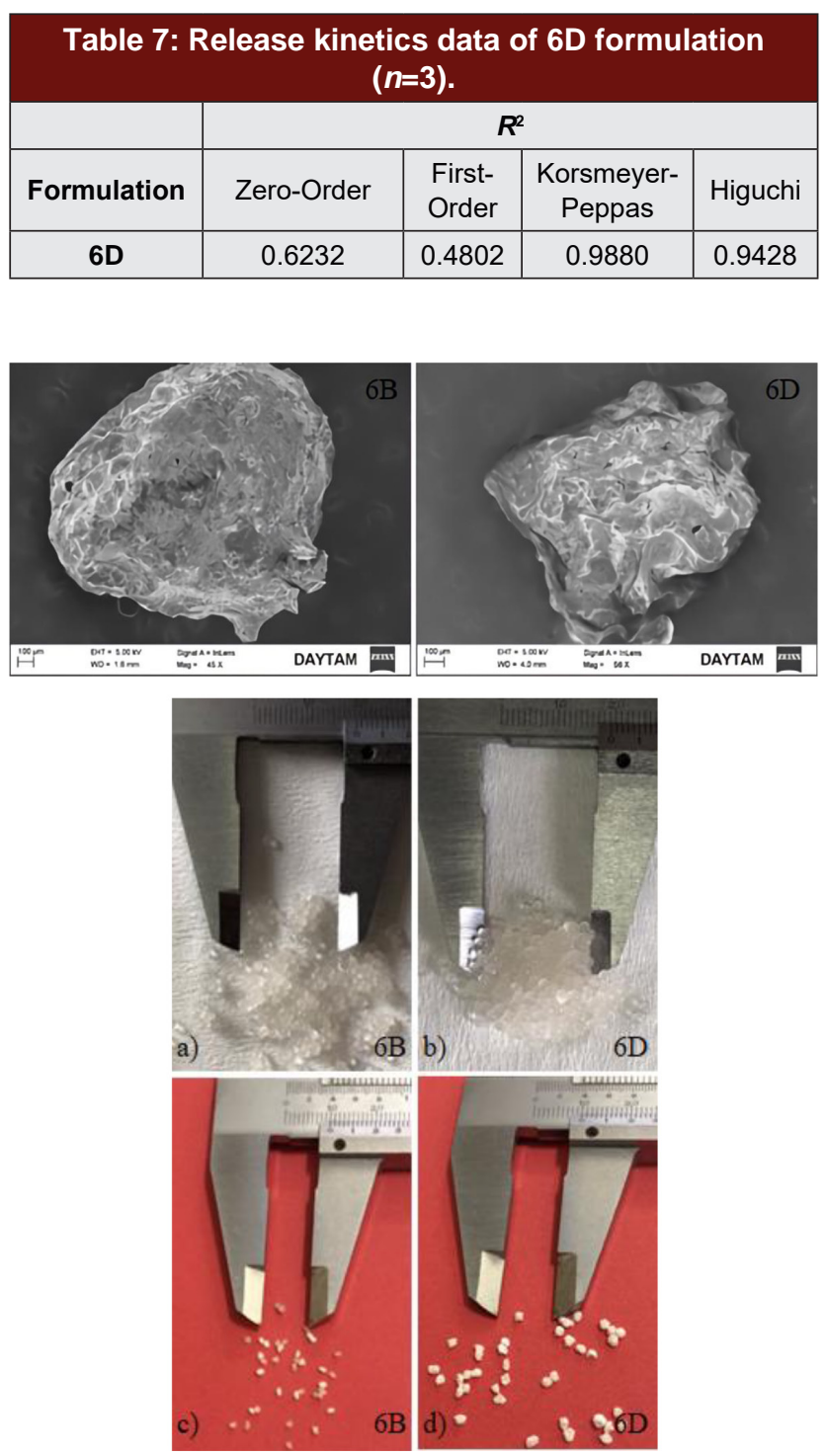

Figure 6: SEM images and digital photos of 6B and 6D formulations freshly prepared $(a, b)$ and after lyophilization (c, d).

This model also shows that drug release is diffusioncontrolled. $^{50}$

\section{Morphological-Organoleptic Control}

After the pre-formulation development studies, all formulations were subjected to organoleptic control. SEM images and digital photos of $6 \mathrm{~B}$ and $6 \mathrm{D}$ formulations freshly prepared and after lyophilization are given in Figure 6. These formulations were found to be spherical with a smooth surface and homogeneous size. Their color is transparent, and the surface is very smooth, as seen in Figure 5. The surfaces of the pellets were determined by SEM images that the 6D hydrogel pellets were rougher and larger than $6 \mathrm{~B}$ hydrogel pellets. The growth of the size is also proof that PG is loaded.
Table 8: BET surface area, average pore diameter and pore volume of $6 B$ and $6 D$ formulations.

\begin{tabular}{|c|c|c|}
\hline & 6B & 6D \\
\hline BET surface area $\left(\mathbf{m}^{2} / \mathbf{g}\right)$ & 1.8836 & 0.0569 \\
\hline Average pore diameter $(\mathbf{n m})$ & 13.4535 & 9.2726 \\
\hline Pore volume $\left(\mathbf{c m}^{3} / \mathbf{g}\right)$ & 0.007468 & 0.006491 \\
\hline
\end{tabular}
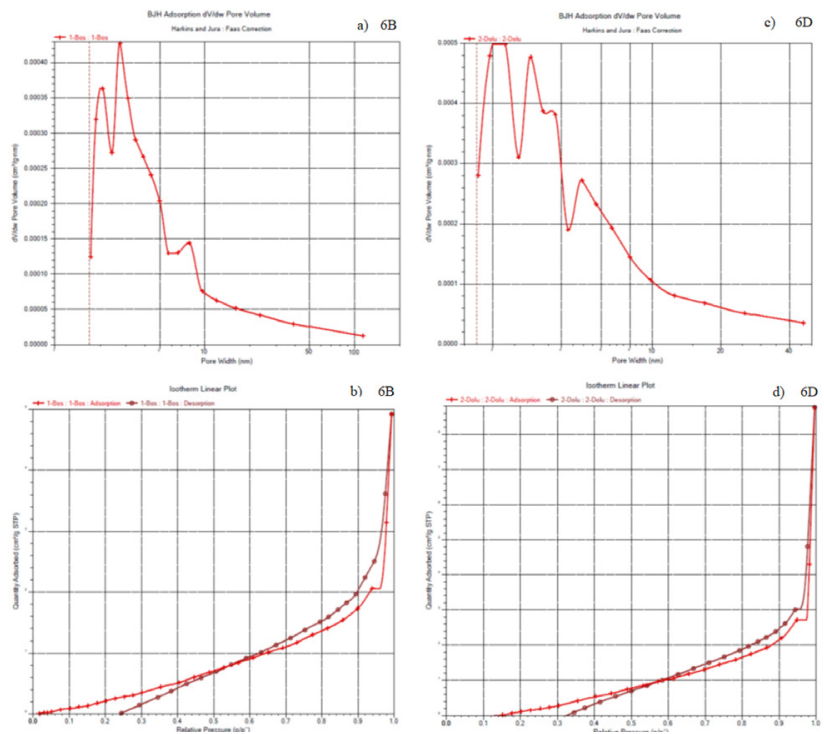

Figure 7: The pore size distributions and N2 adsorptiondesorption isotherms of $6 \mathrm{~B}(\mathrm{a}, \mathrm{b})$ and $6 \mathrm{D}(\mathrm{c}, \mathrm{d})$ formulations.

\section{Determination of Surface Area and Pore Analysis}

The pore characteristics of $6 \mathrm{~B}$ and $6 \mathrm{D}$ floating hydrogel pellets formulations are shown in Table 8. BET surface area, average pore diameter, and pore volume of the $6 \mathrm{~B}$ formulations were $1.8836 \mathrm{~m}^{2} / \mathrm{g}, 13.4535 \mathrm{~nm}$, and $0.007468 \mathrm{~cm}^{3} / \mathrm{g}$, respectively. BET surface area, average pore diameter, and pore volume of the $6 \mathrm{D}$ formulations values were $0.0569 \mathrm{~m}^{2} / \mathrm{g}, 9.2726 \mathrm{~nm}$, and $0.006491 \mathrm{~cm}^{3} / \mathrm{g}$, respectively. The surface area of $6 \mathrm{D}$ formulations is approximately 33 times smaller than blank pellets due to the shrinkage of the pores due to PG loading. Also, the results show that there is a decrease in average pore diameter and pore volume after PG loading. This confirms that PG is located inside the mesoporous channels. Also, this is consistent with a lower size distribution due to their shrinkage. Figure 7 shows the pore size distributions and N2 adsorptiondesorption isotherms of $6 \mathrm{~B}$ and $6 \mathrm{D}$ formulations. As it is understood from the Figure, the isotherm conforms to type IV. Type IV shows a hysteresis loop, i.e., the adsorption and desorption isotherms do not coincide over a certain region of external pressures. The type IV isotherm is typical for mesoporous materials. At low pressures, first, an adsorbate monolayer is formed 
on the pore surface, which is followed by multilayer formation. ${ }^{51}$ According to the International Union of Pure and Applied Chemistry (IUPAC) nomenclature, pores are roughly classified into the following groups: macropores $>50 \mathrm{~nm}$, mesopores in the range of 2.0-50 nm, and micropores $<2.0 \mathrm{~nm}$. The hysteresis loop indicates that the mesoporous structures exist in both $6 \mathrm{~B}$ and $6 \mathrm{D}$ formulations. ${ }^{21}$ When the pore diameters are examined, blank pellets have two pore size distributions around $1.7-114 \mathrm{~nm}$, the first is $1-50 \mathrm{~nm}$ (mesopores), and the second one is $>50 \mathrm{~nm}$ (macropores). But, 6D formulations have a size distribution ranging from 1.7-46 $\mathrm{nm}$. 6D formulations contain no macropore compared to blank pellets. However, we can identify it as mesoporous because it contains very little micropore for the structure. The smaller pore diameters in the
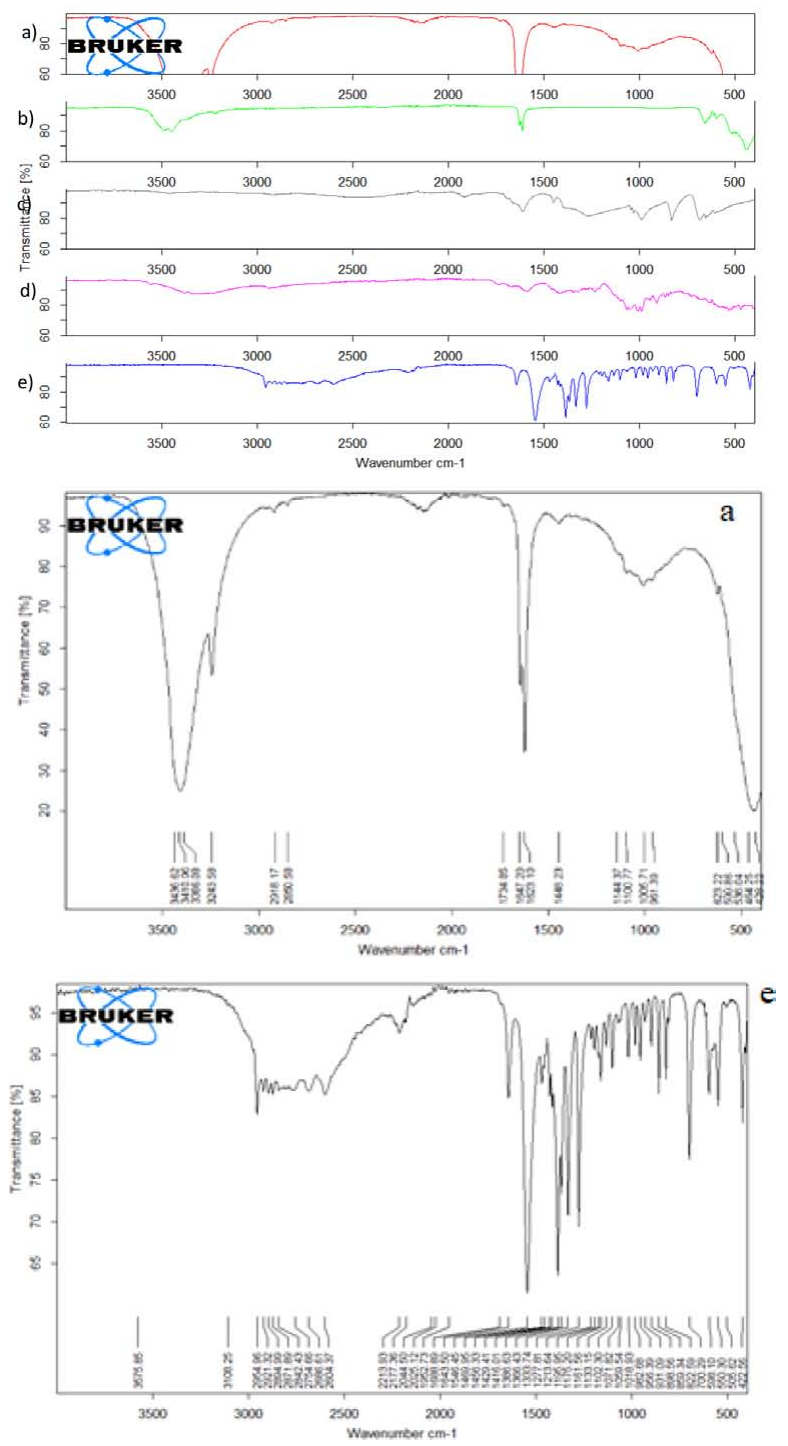

Figure 8: Spectrums of 6D (a), $\mathrm{CaCl}_{2}$ (b), $\mathrm{NaHCO}_{3}$ (c), Pectin (d) and $P G(e)$.

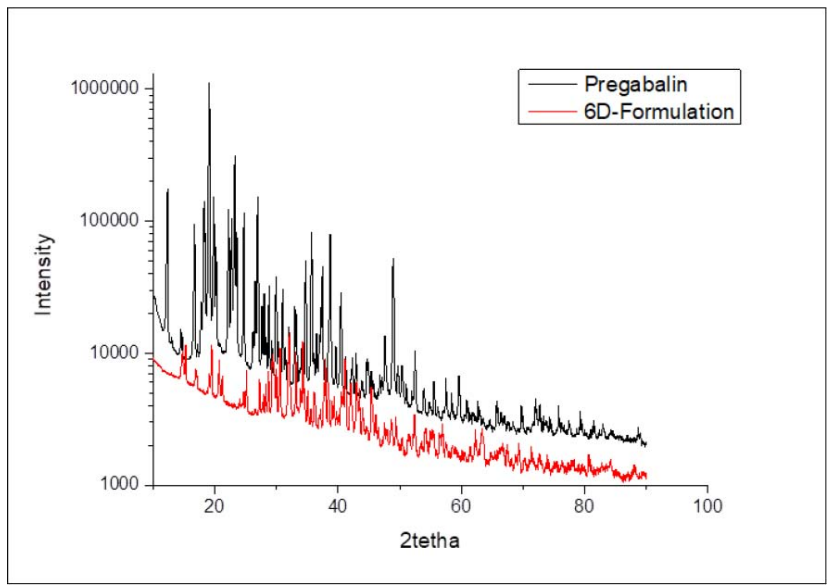

Figure 9: X-ray diffractogram of PG and 6D formulation.

6D formulations also indicate that PG is placed in the structure.

\section{FT-IR Study}

The received spectra of the PG, 6D hydrogel pellet formulation, and formulation excipients are given in Figure 8 below. IR spectra were taken to investigate drug-polymer compatibility. There was no chemical interaction, and the band voltage frequencies belong to the PG spectrum were also detected in the 6D formulation. $2954.96 \mathrm{~cm}^{-1}$ (C-H stretch), $1643.50 \mathrm{~cm}^{-1}$ $\left(\mathrm{N}-\mathrm{H}\right.$ bend, $\mathrm{NH}_{2}$ scissoring), $1546.45 \mathrm{~cm}^{-1}(\mathrm{~N}-\mathrm{O}$ asymmetric stretch), $1469.95 \mathrm{~cm}^{-1}$ (C-H bend), 1333.74 $\mathrm{cm}^{-1}$ (N-O symmetric stretch), $1277.81 \mathrm{~cm}^{-1}$ (C-O stretch), and $931.09 \mathrm{~cm}^{-1}$ (O-H bend) peaks are specific for PG. ${ }^{11,52}$ Some characteristic PG peaks are also included in the $6 \mathrm{D}$ formulation spectrum. It is observed that the decrease in sharp peaks in the $6 \mathrm{D}$ formulation compared to the PG pure peak is entrapped within the pectin pellets, and there appears to be a decrease in peaks due to formulation-forming excipients. In similar studies, this situation is observed for active substances. ${ }^{7,53,54}$

\section{XRD Study}

The determination of the physical state of the drug in the multiple unit systems is important. The $\mathrm{X}$-ray diffraction analysis helps to determine the crystal or amorphous nature of the drugs in drug delivery systems. ${ }^{55} \mathrm{X}$-ray diffractogram of PG and 6D formulation are given in Figure 9. Characteristic crystalline peaks of PG were observed in the diffractogram prominently. The main thermal characteristic sharp peaks of crystalline PG were recorded between 10-50 20. In the 6D formulation diffractogram, characteristic sharp peaks of PG crystals were partially absent. This showed that PG might be present in the amorphous form after its encapsulation in 
the hydrogel pectin formulation. ${ }^{56}$ In a study conducted by Arafa et al., a similar situation was encountered, and sharp peaks were reduced as a result of PG amorphism. ${ }^{57}$

\section{CONCLUSION}

In this research, a new drug-containing formulation has been developed for PG, which is prescribed for neuropathic pain, post-herpetic neuralgia, radicular pain, and fibromyalgia. Formulations have been developed by the ionotropic gelation method using fewer excipients which is a simple, reproducible, and easily adaptable method to the industry. The formulations have been successfully characterized by evaluating many parameters. The strong crosslinking of the pectin with the calcium salt resulted in a prolonged release. With this study, a sustained release has been achieved owing to pectin pellets, which can release for $24 \mathrm{~h}$ in the contents of the stomach. Unlike extended-release preparations containing PG, available in the pharmaceutical market, this release was achieved without using any film coating agent. Optimum results were obtained in characterization studies. As a result of BET analysis, it has been proven that the structure is porous and there is no change in the chemical and crystal structure of PG by FT-IR and XRD studies. It is thought that this study will be an alternative dosage form that patients with neuropathic pain can benefit from, with fewer doses and fewer side effects.

\section{ACKNOWLEDGEMENT}

The author would like to gratefully acknowledge the kind support of students Meryem AKTAŞ and Emrah SEYRET.

\section{CONFLICT OF INTEREST}

The authors declare that there is no conflict of interest.

\section{ABBREVIATIONS}

PG: Pregabalin; FT-IR: Fourier Transform Infrared; SEM: Scanning Electron Microscopy; BET: BrunauerEmmett-Teller; XRD: X-ray diffraction; $\mathbf{N a H C O}_{3}$ : sodium bicarbonate; $\mathbf{C O}_{2}$ : carbon dioxide; GABA: gamma-aminobutyric acid; $\mathbf{C a C l}_{2}$ : calcium chloride; HCl: hydrochloric acid; HPLC: High Pressure Liquid Chromatography; $\mu \mathrm{g}$ : microgram; mL: milliliter; $\mu \mathrm{m}$ : micrometer; LOD: limit of detection; LOQ: the limit of quantification; rpm: revolutions per minute; M: molar; ${ }^{\circ} \mathbf{C}$ : degree Centigrade; USP30/NF25: United States of Pharmacopoeia/National Formulary; BJH: BarrettJoiner-Halenda; ${ }^{\circ} \mathbf{K}$ : degree Kelvin; cm: centimeter;
kV: kilovolt; $\mathbf{m A}$ : miliAmper; $\mathbf{n m : ~ n a n o m e t e r ; ~ m i n : ~}$ minutes; g: gram; mm: milimeter; h: hour.

\section{REFERENCES}

1. Kantharao CKS, Leelakrishna J, Anusha J, Asha B, Bhavani B. Diclofenac orodispersible tablets: Formulation and in vitro evaluation. Ann Clin Lab Res. 2019;7:1-8. DOI: 10.21767/2386-5180.100287.

2. Chowdary KPR, Chaitanya CKL. Recent research on floating drug delivery systems-A review. J Glob Trends Pharm Sci. 2014;5:1361-73.

3. Patil H, Tiwari RV, Repka MA. Recent advancements in mucoadhesive floating drug delivery systems: A mini-review. J Drug Deliv Sci Technol. 2016;31:65-71. DOI: 10.1016/j.jddst.2015.12.002.

4. Mayavanshi AV, Gajjar SS. Floating drug delivery systems to increase gastric retention of drugs: A review. Res J Pharm Technol. 2008;1:345-8.

5. Khan DA, Bajpai MB. Floating drug delivery system: An overview. Int J PharmTech Res. 2010;2:2497-505.

6. Shah SH, Patel JK, Patel NV. Stomach specific floating drug delivery system: A review. Int J PharmTech Res. 2009;1:623-33.

7. Jadi RK, Tatikonda A, Reedy PRV, Venisetty RK. Design and characterization of pregabalin swellable core osmotic pumps. Int J Pharm Res Alli. 2016;5:815.

8. Velavan P, Venkatesan P. Preformulation parameters characterization to design, development and formulation of pregabalin loaded nanoparticles. J Pharm Sci Res. 2014;6:436-40.

9. Fukasawa H, Muratake H, Nagae M, Sugiyama K, Shudo K. Transdermal administration of aqueous pregabalin solution as a potential treatment option for patients with neuropathic pain to avoid central nervous system-mediated side effects. Biol Pharm Bull. 2014;37(11):1816-9. DOI: 10.1248/bpb.b1400278.

10. Sher N, Fatima N, Perveen S, Siddiqui FA, Wafa Sial A. Pregabalin and tranexamic acid evaluation by two simple and sensitive spectrophotometric methods. Int J Anal Chem. 2015;2015:241412. DOI: 10.1155/2015/241412.

11. Kanwar N, Kumar R, Sarwal A, Sinha VR. Preparation and evaluation of floating tablets of pregabalin. Drug Dev Ind Pharm. 2016;42(4):654-60. DOI: 10.3109/03639045.2015.1062895.

12. Azmi S, ElHadd KT, Nelson A, Chapman A, Bowling FL, Perumbalath A, Lim $\mathrm{J}$, Marshall A, Malik RA, Alam U. Pregabalin in the management of painful diabetic neuropathy: A narrative review. Diabetes Ther. 2019;10(1):35-56. DOI: 10.1007/s13300-018-0550-x.

13. Rahat Dahmardeh A, Moosavi A, Nasir-Al-Din Tabatabaei SM, Ordoni Avval $J$, Sistanizad $M$. The effect of a single dose oral pregabalin on hemodynamic changes and duration of analgesia after spinal anesthesia in orthopedic surgeries of tibial fractures. Iran J Pharm Res. 2018;17(Suppl):2-7.

14. Alvarez-Lorenzo C, Blanco-Fernandez B, Puga AM, Concheiro A. Crosslinked ionic polysaccharides for stimuli-sensitive drug delivery. Adv Drug Deliv Rev. 2013;65(9):1148-71. DOI: 10.1016/j.addr.2013.04.016.

15. Sriamornsak P. Investigation of pectin as a carrier for oral delivery of proteins using calcium pectinate gel beads. Int J Pharm. 1998;169(2):213-20. DOI: 10.1016/S0378-5173(98)00129-X.

16. Sriamornsak $P$, Nunthanid J. Calcium pectinate gel beads for controlled release drug delivery: I. Int J Pharm. 1998;160(2):207-12. DOI: 10.1016/ S0378-5173(97)00310-4.

17. Sriamornsak P. Chemistry of pectin and its pharmaceutical uses: A review. Silpakorn Univ Int J. 2003:206-28.

18. Racoviţă S, Vasiliu S, Popa M, Luca C. Polysaccharides based on microand nanoparticles obtained by ionic gelation and their applications as drug delivery systems. Rev Roum Chim. 2009;54:709-18.

19. Sevinç Özakar R, Aktaş Y, Bilici D, Ayyıldız A. Physicochemical characterization and microbiological evaluation of tetracycline $\mathrm{HCl}$ loaded chitosan beads for periodontitis treatment: A preliminary study. J Allied PharmSci. 2017;1:28-34. DOI: 10.29199/JAPS.101017.

20. Sriamornsak $P$, Nunthanid J. Calcium pectinate gel beads for controlled release drug delivery: II. Effect of formulation and processing variables on drug release. J Microencapsul. 1999;16(3):303-13. DOI: $10.1080 / 026520499289031$. 
21. Veronovski A, Tkalec G, Knez Ž, Novak Z. Characterisation of biodegradable pectin aerogels and their potential use as drug carriers. Carbohydr Polym. 2014;113:272-8. DOI: 10.1016/j.carbpol.2014.06.054, PMID 25256485.

22. Choudhury PK, Panigrahi GS, Pradhan KK, Panda CK, Pasa GS. Design, development and evaluation of furosemide loaded micro pellets prepared by ionotropic gelation method. Int J PharmTech Res. 2010;2:420-6.

23. Sedighikamal $H$, Zarghami R, Khadiv-Parsi P, Mostoufi N. Sustained release coating of ibuprofen pellets at Wurster fluidization: Statistical approach. J Pharm Investig. 2015;45(4):341-7. DOI: 10.1007/s40005-015-0177-0.

24. Kumari MH, Samatha K, Balaji A, Shankar MSU. Recent novel advancements in pellet formulation: A review. Int J Pharm Sci Res. 2013;4:3803-22. DOI: 10.13040/IJPSR.0975-8232.4(10).3803-22.

25. Anil Mohan J, Rajkumar B, Bhavya T, Ashok Kumar A. RP-HPLC method development and validation for the simultaneous quantitative estimation of pregabalin, mecobalamin and alpha-lipoic acid in capsules. Int J Pharm Pharm Sci. 2014;6:270-7.

26. Udayalakshmi $P$, Muthukumaran $M$, Krishnamoorthy B. Simultaneous estimation of pregabalin and methylcobalamin by RP-HPLC in bulk drug and combined tablet dosage form. Int J Pharm H Care Res. 2014;2:74-80.

27. Sreekanth D, Ramya P, Vishwanadham Y, Vanitha R. Development and method validation of RP-HPLC for simultaneous determination of pregabalin and methylcobalamin in pure and pharmaceutical dosage form. Asia Jour Rese Chem. 2017;10(4):557-65. DOI: 10.5958/0974-4150.2017.00092.X.

28. Kavitha N, Shilpa K, Ajitha A, Rao UM. Development and validation of RPHPLC method for simultaneous estimation citicoline and methylcobalamin in tablet dosage form. Int J Univers Pharm Bio Sci. 2014;3:114-23.

29. Muhamad II, Fen LS, Hui NH, Mustapha NA. Genipin-cross-linked kappa-carrageenan/carboxymethyl cellulose beads and effects on betacarotene release. Carbohydr Polym. 2011;83(3):1207-12. DOI: 10.1016/j. carbpol.2010.09.021.

30. Ren H, Gao Z, Wu D, Jiang J, Sun Y, Luo C. Efficient $\mathrm{Pb}(\mathrm{II})$ removal using sodium alginate-carboxymethyl cellulose gel beads: Preparation, characterization, and adsorption mechanism. Carbohydr Polym. 2016;137:402-9. DOI: 10.1016/j.carbpol.2015.11.002.

31. Shirizadeh B, Maghsoodi M, Alami-Milani M, Salatin S, Jelvehgari M. Tailored hydrogel microbeads of sodium carboxymethylcellulose as a carrier to deliver mefenamic acid: Transmucosal administration. Jundishapur J Nat Pharm Prod. 2017;12(4):e65324. DOI: 10.5812/jjnpp.65324.

32. Liu Y, Chen L, Zhou C, Yang J, Hou Y, Wang W. Development and evaluation of alginate-chitosan gastric floating beads loading with oxymatrine solid dispersion. Drug Dev Ind Pharm. 2016;42(3):456-63. DOI: 10.3109/03639045.2015.1088866.

33. Ahmed A, Yadav HKS, Manne N, Sureddy VL, Namburi NBV, Shivakumar HG. Formulation and evaluation of enteric coated nanoparticulate system for poorly absorbable drug. J Drug Deliv Sci Technol. 2014;24(1):50-6. DOI: 10.1016/S1773-2247(14)50007-X.

34. Karki S, Kim H, Na SJ, Shin D, Jo K, Lee J. Thin films as an emerging platform for drug delivery. Asian J Pharm Sci. 2016;11(5):559-74. DOI: 10.1016/j.ajps.2016.05.004.

35. Jiang H, Tian R, Hu W, Jia Y, Yuan P, Wang J, Zhang L. Formulation and evaluation of gastroretentive floating drug delivery system of dipyridamole. Drug Dev Ind Pharm. 2015;41(4):674-80. DOI: 10.3109/03639045.2014.893355.

36. Jelvehgari M, Montazam SH, Soltani S, Mohammadi R, Azar K, Montazam SA. Fast dissolving oral thin film drug delivery systems consist of ergotamine tartrate and caffeine anhydrous. Pharm Sci. 2015;21(2):102-10. DOI: 10.15171/PS.2015.24.

37. Kumar MK, Nagaraju K, Bhanja S, Sudhakar M. Formulation and evaluation of sublingual tablets of terazosin hydrochloride. Int J Pharm Sci Res. 2014;5:417-27. DOI: 10.13040/IJPSR.0975-8232.5(2).417-27.

38. Bhardwaj P, Chaurasia H, Chaurasia D, Prajapati SK, Singh S. Formulation and in-vitro evaluation of floating microballoons of indomethacin. Acta Pol Pharm. 2010;67(3):291-8.

39. Kathpalia $H$, Gupte A. An introduction to fast dissolving oral thin film drug delivery systems: A review. Curr Drug Deliv. 2013;10(6):667-84. DOI: 10.217 4/156720181006131125150249.

40. Zhu J, Zhong L, Chen W, Song Y, Qian Z, Cao X, Huang Q, Zhang B, Chen $\mathrm{H}$, Chen W. Preparation and characterization of pectin/chitosan beads containing porous starch embedded with doxorubicin hydrochloride:
A novel and simple colon targeted drug delivery system. Food Hydrocoll. 2019;95:562-70. DOI: 10.1016/j.foodhyd.2018.04.042.

41. Zhang L, Cao F, Ding B, Li Q, Xi Y, Zhai G. Eudragit $囚$ S100 coated calcium pectinate microspheres of curcumin for colon targeting. J Microencapsul. 2011;28(7):659-67. DOI: 10.3109/02652048.2011.604436.

42. Hiorth M, Versland T, Heikkilä J, Tho I, Sande SA. Immersion coating of pellets with calcium pectinate and chitosan. Int J Pharm. 2006;308(1-2):2532. DOI: 10.1016/j.jpharm.2005.10.012.

43. Patil JS, Kamalapur MV, Marapur SC, Kadam DV. Ionotropic gelation and polyelectrolyte complexation: The novel techniques to design hydrogel particulate sustained, modulated drug delivery system: A review. Dig J Nanomater Bios. 2010;5:241-8.

44. Choi BY, Park HJ, Hwang SJ, Park JB. Preparation of alginate beads for floating drug delivery system: Effects of $\mathrm{CO} 2$ gas-forming agents. Int $\mathrm{J}$ Pharm. 2002;239(1-2):81-91. DOI: 10.1016/S0378-5173(02)00054-6.

45. Abou el Ela Ael S, Hassan MA, El-Maraghy DA. Ketorolac tromethamine floating beads for oral application: Characterization and in vitro/in vivo evaluation. Saudi Pharm J. 2014;22(4):349-59. DOI: 10.1016/j. jsps.2013.06.006.

46. Radwan MA, Abou el Ela Ael S, Hassan MA, El-Maraghy DA. Pharmacokinetics and analgesic effect of ketorolac floating delivery system. Drug Deliv. 2015;22(3):320-7. DOI: 10.3109/10717544.2014.883189.

47. Kim S, Hwang KM, Park YS, Nguyen TT, Park ES. Preparation and evaluation of non-effervescent gastroretentive tablets containing pregabalin for oncedaily administration and dose proportional pharmacokinetics. Int J Pharm. 2018;550(1-2):160-9. DOI: 10.1016/j.ijpharm.2018.08.038.

48. Whitehead L, Collett JH, Fell JT. Amoxycillin release from a floating dosage form based on alginates. Int J Pharm. 2000;210(1-2):45-9. DOI: 10.1016/ s0378-5173(00)00567-6.

49. Ibrahim M, Naguib YW, Sarhan HA, Abdelkader H. Gastro-retentive oral drug delivery systems: A promising approach for narrow absorption window drugs. J Adv Biomed Pharm Sci. 2019;2:0. DOI: 10.21608/jabps.2019.11357.1042.

50. Abou Youssef NAH, Kassem AA, El-Massik MAE, Boraie NA. Development of gastroretentive metronidazole floating raft system for targeting Helicobacter pylori. Int J Pharm. 2015;486(1-2):297-305. DOI: 10.1016/j. ijpharm.2015.04.004.

51. Bizarro M, Rodil SE. Physicochemical characterization of photocatalytic materials. In: Hernández-Ramírez A, Medina-Ramírez I, editors. Photocatalytic semiconductors: Synthesis, characterization, and environmental applications. Berlin: Springer International Publishing; 2015. p: 127.

52. Lamichhane S, Park JB, Sohn DH, Lee S. Customized novel design of 3D printed pregabalin tablets for intra-gastric floating and controlled release using fused deposition modeling. Pharmaceutics. 2019;11(11):564. DOI: 10.3390/pharmaceutics11110564.

53. Brijesh P, Ratnakar N. Formulation, development and evaluation of sustained release beads of pregabalin. World J Pharm Pharm Sci. 2017;6:1604-18.

54. Ghumman SA, Bashir S, Noreen S, Khan AM, Malik MZ. Taro-corms mucilage-alginate microspheres for the sustained release of pregabalin: In vitro and in vivo evaluation. Int J Biol Macromol. 2019;139:1191-202. DOI: 10.1016/j.ijbiomac.2019.08.100.

55. Sevinç Özakar R, Özakar E. Current overview of oral thin films. Turk J Pharm Sci. 2021;18(1):111-21. DOI: 10.4274/tjps.galenos.2020.76390.

56. Taksande JB, Umekar MJ. Preparation of intranasal pregabalin microspheres: In vitro, ex vivo and in vivo pharmacodynamic evaluation. J Pharm Res. 2018;12:112-21.

57. Arafa MG, Ayoub BM. DOE Optimization of nano-based carrier of pregabalin as hydrogel: New therapeutic and chemometric approaches for controlled drug delivery systems. Sci Rep. 7:41503. DOI: 10.1038/srep41503. 
PICTORIAL ABSTRACT

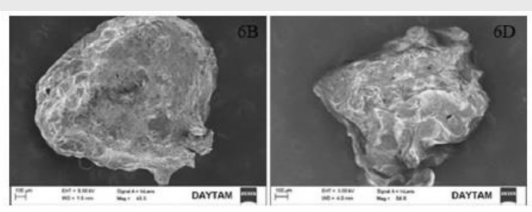

SEM images of $6 \mathrm{~B}$ and $6 \mathrm{D}$ formulations

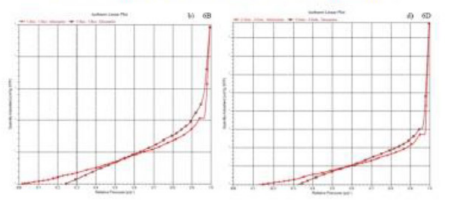

$\mathrm{N} 2$ adsorption-desorption isotherms of $6 \mathrm{~B}$ and $6 \mathrm{D}$ formulations

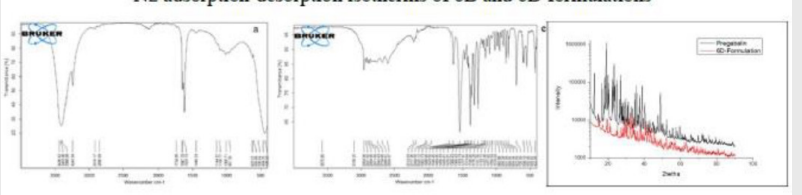

FT-IR spectrums and X-ray diffractograms of PG (a) and 6D formulation (e)

\section{About Author}

Rukiye Sevinç Özakar is an Assistant Professor. She is working in the area of nano-sized drug delivery systems, gastroretentive drug delivery systems, thin film formulations and gel systems, etc. She has a silver medal patent award from 5th Istanbul International Inventions Fair, ISIF-2020, TURKEY.

\section{SUMMARY}

Floating drug systems are useful systems that can increase the duration of drugs in the stomach. Floating systems are low-density systems with sufficient lifting power that can float for an adequate time without being affected by gastric content and emptying of the stomach and remain floating in the stomach for a long time. Pregabalin is similar to gamma-aminobutyric acid (GABA), which is the neurotransmitter of mammals with both structural and pharmacological properties. Its primary effect is anticonvulsant, and it is used in epilepsy. In this study, floating pellet systems, which have been studied frequently today, were developed and characterized for pregabalin and bring a new approach to widely used oral drug therapy. The strong crosslinking of the pectin with the calcium salt resulted in a prolonged release. With this study, a sustained release has been obtained, which can release for $24 \mathrm{~h}$ in the contents of the stomach. This release profile was achieved without using any film coating agent. As a result of BET analysis, it has been proven that the structure is porous, and there is no change in the chemical and crystal structure of PG by FT-IR and $\mathrm{XRD}$ studies. It is thought that these pellets will be an alternative dosage form that patients with neuropathic pain can benefit from, with fewer doses and fewer side effects.

Cite this article: Sevinç Özakar R. Development and in vitro Characterization of Gastroretentive Formulations as Calcium Pectinate Hydrogel Pellets of Pregabalin by lonotropic Gelation Method. Indian J of Pharmaceutical Education and Research. 2022;56(1s):s9-s20. 